\title{
Más evidencias a favor del uso de diuréticos y beta bloqueantes como tratamiento de primera línea en la hipertensión arterial
}

Psaty BM, Smith NL, Siscovick DS et al. Health Outcomes Associated with Antihypertensive Therapies Used as FirstLine Agents. JAMA 1997; 227:739:745.

\section{Objetivo}

Revisar la evidencia científica en relación a la seguridad y eficacia de diferentes drogas usadas como primera línea antihipertensiva en la reducción de eventos cardiovasculares.

\section{Fuente y Selección de Datos}

Los autores limitaron la búsqueda a las 4 clases de antihipertensivos mas usados: diuréticos, b-bloqueantes, bloqueantes cálcicos e inhibidores de la enzima convertidora de angiotensina (IECA). Se revisó MEDLINE desde 1980 a 1995, incluyendo:1) estudios clínicos controlados y randomizados, con al menos un año de seguimiento, y que sólo compararan una droga activa contra placebo en la reducción de eventos clínicos. Dado que no se encontraron estudios con bloqueantes cálcicos e IECA que compararan incidencia de complicaciones clínicas, fueron seleccionados los estudios randomizados más importantes cuyo punto final fuera la reducción de la presión arterial, calidad de vida, hipertrofia ventricular izquierda, etc, 2) meta-análisis previos, 3) estudios observacionales evaluando infarto miocárdico o ACV. Para el metaanálisis se usaron los mejores resultados de la combinación de los riesgos relativos de los estudios incluídos.

\section{Resultados Principales}

Los b-bloqueantes y los diuréticos fueron evaluados en 18 estudios. Los b-bloqueantes disminuyeron el riesgo de ACV: RR 0.71 (IC 95\% 0.59-0.86) y de insuficiencia cardíaca congestiva (ICC) RR 0.58 (IC 95\% 0.40-0.84). Los ha- llazgos fueron similares para los diuréticos en altas dosis (> $50 \mathrm{mg}$ ): para ACV RR: 0.49 (IC 95\% 0.39-0.62), para ICC RR: 0.17 (IC 95\% 0.07-0.41). Los diuréticos en bajas dosis ( $<25 \mathrm{mg}$ ) no sólo previnieron ACV RR: 0.66 (IC 95\% 0.55-0.78) e ICC RR: 0.58 (IC 95\% $0.44-0.76$ ) sino tambien enfermedad coronaria RR: 0.72 (IC $95 \% 0.61-0.85$ ) y mortalidad global RR: 0.90 (IC 95\% 0.81-0.99). A pesar de que los bloqueantes cálcicos y los IECA redujeron la presión en los hipertensos, no se observaron evidencias respecto a la disminución de eventos clínicos. Por el contrario, la evidencia muestra, para el caso de los bloqueantes cálcicos de acción corta, mayor incidencia de infarto de miocardio. Respecto a la indicación de estás últimas drogas en circunstancias especiales, podemos resumirlas así: en la enfermedad coronaria algunos bloqueantes cálcicos como la nifedipina, mostraron aumento de la incidencia de infarto miocárdico y los IECA, reducción de la morbimortalidad en ICC RR: 0.77 (IC 95\% 0.67-0.88) y disminución de la nefropatía diabética. Para el resto de las "indicaciones especiales" tales como dislipidemia, insuficiencia renal, prostatismo, fibrilación auricular, no hay evidencia suficiente para recomendar alguna droga en particular.

\section{Conclusiones}

Hasta que se disponga de datos provenientes de estudios randomizados sobre la reducción de eventos clínicos de los IECA y bloqueantes cálcicos, la evidencia actual apoya a la mayoría de las guías clínicas que recomiendan el uso de los bbloqueantes y los diuréticos en bajas dosis como primera línea en el tratamiento de la hipertensión arterial.

Apoyo económico: Agencias de salud estatales de EE.UU y laboratorio Merck.

\section{Comentario}

Si bien ya en 1993 el comité americano sobre detección, evaluación y tratamiento de la hipertensión arterial, como otras guías internacionales, recomendaron los diuréticos y los b-bloqueantes como primera elección terapéutica, los bloqueantes cálcicos y los IECA siguen siendo extensamente usados como primera línea de tratamiento, especialmente en nuestro país. Este metaanálisis analizó fundamentalmente estudios que tuvieran eventos clínicos como punto final y no resultados intermedios como la reducción de la presión arterial. Esta diferencia no es trivial ya que en medicina los resultados epidemiológicos no están necesariamente asociados a los fenómenos biológicos. Las drogas tienen una multiplicidad de efec- tos diferentes de la acción farmacológica de interés, entre ellos, efectos colaterales molestos y a veces peligrosos. Esto es tan así que a pesar de que los bloqueantes cálcicos reducen la presión al igual que otras drogas, hay estudios tanto de prevención secundaria como primaria del infarto de miocardio que demuestran aumento de los mismos con estas drogas. Para citar otro famoso ejemplo de discordancia entre acción biológica y resultado epidemiológico, la observación de que las extrasístoles ventriculares luego del infarto miocárdico aumentaban la incidencia de muerte súbita sumado al desarrollo de drogas que suprimían esta arritmia, fue suficiente evidencia para la prescripción generalizada de antiarrítmicos en el post-in- farto. Estudios posteriores demostraron un aumento y no una disminución del riesgo de morir con estas drogas(1). Por lo tanto parece atinado seguir recomendando como primera línea de tratamiento de la hipertensión arterial los diuréticos y b-bloqueantes.

\section{Dr. Adolfo Rubinstein Unidad de Medicina Familiar y Preventiva}

Hospital Italiano de Buenos Aires

\section{Referencias}

1.Echt DS, Liebson PR, Mitchell B, et al. Mortality and Morbidity in Patients Receiving Encainide, Flecainide, or Placebo: The Cardiac Arrhytmia Supression Trial. N Eng J Med 1991; 324:781-788. 